\title{
A educação profissional no contexto da sociedade capitalista brasileira: análise a partir do método crítico-dialético
}

\begin{abstract}
Resumo: A intenção deste ensaio é recolocar o marxismo como opção epistemológica, teórica, metodológica e política no campo do debate da educação, particularmente, da educação profissional. Procuramos, esquematicamente, apresentar três dimensões articuladas, que denominamos de impasses da educação profissional frente ao capitalismo periférico no Brasil. Inicialmente discutimos o campo simbólico como campo de expressão das ideologias que sustentam o capitalismo e que utiliza, dentre outras estratégias, o silenciamento sobre o marxismo, e mesmo sobre o capitalismo, no sentido de esvaziar a crítica e o questionamento político. Em seguida relacionamos esses mecanismos à educação profissional, identificando como o capitalismo neoliberal opera. Também apresentamos alguns fundamentos filosóficos, teóricos e metodológicos da "teoria da práxis", mostrando a indissociabilidade entre teoria crítica e ação transformadora. Por fim, nas considerações finais reafirmamos a posição inicial em recolocar o marxismo como instrumental fundamental na compreensão das políticas educacionais, já que estão imersas na sociedade capitalista contemporânea, hoje hegemônica.
\end{abstract}

Palavras-Chave: Educação profissional. Capitalismo neoliberal. Trabalho. Teoria da práxis. Políticas educacionais.

\section{Introdução}

O presente ensaio toma como referência os estudos que temos realizado desde 1998, quando participamos da equipe de avaliação externa do Plano Estadual de Qualificação Profissional - Planfor/ BA, que posteriormente torna-se nosso objeto de investigação no doutorado. Nessa mesma época integramos o corpo técnico do Centro de Recursos Humanos da Universidade Federal da Bahia (CRH/UFBA), como membro do grupo de pesquisa Trabalho, Trabalhadores e Reprodução Social, coordenado pela professora Graça Druck.

Concluído o doutorado, a partir do segundo semestre de 2005, quando retomamos, integralmente, as nossas atividades docentes na Faculdade de Educação, passamos a nos responsabilizar por duas disciplinas do currículo do Curso de Pedagogia - Trabalho e Educação e Educação Profissional - e orientar trabalhos monográfi$\cos ^{1}$ nessa área. Atualmente, somos membro da Linha de Pesquisa - Educação: História, Trabalho e Sociedade, do Programa de Pós-graduação em Educação da UFBA, orientando três mestrandas, cujos estudos concentram-se na área da educação profissional.
Maria Regina Filgueiras Antoniazzi

Doutora em Ciências Sociais pela Universidade Federal da Bahia. Atualmente é professora adjunta da Faculdade de Educação da UFBA, atuando no ensino de graduação e de pós-graduação.

(1) Atualmente são três os estudos monográficos sob minha orientação: O Projovem Urbano/ Salvador, Trabalhadores de uma determinada Call Center de Salvador e Cursos Gratuitos oferecidos pelo Senac/Salvador. 
A intenção deste ensaio é recolocar o marxismo como nossa opção epistemológica, teórica, metodológica e política no campo do debate da educação, particularmente, da educação profissional, pois ao contrário das aparências nunca esteve tanto na ordem do dia, já que a análise das leis de movimento do capital e as descobertas de Marx, na segunda metade do século XIX, continuam válidas até hoje, apesar de terem sido produzidas há mais de cento e cinquenta anos, exatamente porque nossa sociedade continua sendo regida pelos ditames do capital.

É preciso reconhecer que nesse longo período a sociedade burguesa sofreu transformações profundas, emergindo fenômenos e processos que não foram estudados por Marx, contudo eles foram alvo de pesquisa de analistas que, inspirados por Marx, e, principalmente, incorporando seu método crítico-dialético, procuraram esclarecê-los e integrá-los ao corpo teórico de O Capital, constituindo o que se pode designar de Economia Política marxista.2 Essa concepção toma como referência o enunciado por Engels (1972) como a ciência das leis que regem a produção e a troca dos meios materiais de subsistência na sociedade humana, acrescida pela ênfase posta por Lênin (1982), indicando que o objeto da Economia Política não é simplesmente a produção, porém as relações sociais que existem entre os homens na produção, isto é, a estrutura social de produção. (NETTO; BRAZ, 2008, p. 26). Nesse sentido, afirmam os mesmos autores,

[...] o objetivo da Economia Política é o estudo das leis sociais que regulam a produção e a distribuição dos meios que permitem a satisfação das necessidades dos homens, historicamente determinados. Tais meios - que em seu conjunto, representam a riqueza social - asseguram aquela satisfação, sem a qual a sociedade não pode manter-se e reproduzir-se. Assim, pois, o objeto da Economia Política são as relações sociais próprias à atividade econômica, que é o processo que envolve a produção e a distribuição dos bens que satisfazem as necessidades individuais ou coletivas dos membros de uma sociedade. (NETTO; BRAZ, 2008, p. 29).

E, na base da atividade econômica está o trabalho, tornando possível a produção de qualquer bem, criando os valores que constituem a riqueza social. Contudo, o trabalho é muito mais que um elemento teórico da Economia Política, pois diz respeito ao próprio 
modo de ser dos homens e da sociedade. Nesse sentido, outras determinações o fazem categoria central para a compreensão do próprio fenômeno humano-social. (NETTO; BRAZ, 2008)

O trabalho é, sempre, atividade coletiva, pois o sujeito se insere num conjunto maior de outros sujeitos, que exige não só a coletivização de conhecimentos, mas, sobretudo essa atividade implica obrigar ou convencer outros à realização de atividades, organizar e distribuir tarefas, estabelecer ritmos etc., o que só é possível pela comunicação propiciada pela linguagem articulada. Netto e Braz (2008) corroboram explicando que:

[...] O trabalho implica mais que a relação sociedade/natureza: implica uma interação no marco da própria sociedade, afetando os seus sujeitos e a sua organização. O trabalho, através do qual o sujeito transforma a natureza [...] trata-se de uma transformação prática, [e] transforma também o seu sujeito: foi através do trabalho que, de grupos primatas, surgiram os primeiros grupos humanos - numa espécie de salto que fez emergir um novo tipo de ser, distinto do ser natural (orgânico e inorgânico): o ser social.

Portanto, retornar a Marx, no caso específico do estudo e compreensão da educação profissional, hoje, é fundamental, pois continuamos, na sociedade brasileira contemporânea, sendo regidos pelo modo de produção capitalista. Outra razão de retornarmos a Marx é que um dos elementos de nossa crise teórica, na nossa compreensão, é o fato de que Marx continua sendo muito citado, contudo é cada vez menos lido, tanto pelos que o atacam quanto por muitos que o defendem.

Embora Marx nunca tenha escrito um texto, folheto, livro ou artigo dedicado expressamente ao tema do ensino e da educação, concordamos com Rubens E. Frias ${ }^{3}$ (2004), tradutor dos textos sobre educação e ensino de Marx e Engels, quando afirma que as referências que fazem sobre essas questões aparecem separadas ao longo de sua obra, portanto, não é possível "levantar" um sistema pedagógico ou educativo completo e elaborado. Contudo, isso não significa que essas referências sejam simples opiniões conjunturais, desprezíveis do ponto de vista teórico, pois nunca perderam de vista a totalidade e as circunstâncias históricas.

Assim, a discussão que empreendemos nesse ensaio para analisar a educação profissional toma como suposto que a essência 
humana só pode ser descoberta na existência social e histórica dos indivíduos, isto é, no conjunto das relações sociais concretas, que tem como base o trabalho. Entendemos que, em sua origem e essência, a educação é, primariamente, um processo material, ao qual correspondem constelações da relação sujeito-objeto. Portanto, tem funções socioeconômicas, mas não é um mero apêndice do sistema de produção. Ao contrário, faz parte, também, do mundo da produção.

A partir desse suposto, vemos a participação da educação em todos os elementos constitutivos do processo de reprodução social: na produção, nas relações de distribuição e intercâmbio e no consumo social. Consideramos, portanto que a educação cumpre uma importante função social de mediação fundamental na acumulação, organização, apropriação e transmissão de conhecimento e de valores éticos, no enriquecimento das experiências sociais e no desenvolvimento do ser social.

Este ensaio está estruturado, esquematicamente, em três dimensões articuladas, que denominamos de impasses da educação profissional frente ao capitalismo periférico no Brasil. Assim, inicialmente, discutimos o campo simbólico como campo de expressão das ideologias que sustentam o capitalismo e que utiliza, dentre outras estratégias, o silenciamento sobre o marxismo, e mesmo sobre o capitalismo, no sentido de esvaziar a crítica e o questionamento político. Em seguida relacionamos esses mecanismos à educação profissional, identificando como o capitalismo neoliberal opera. Também apresentamos alguns fundamentos filosóficos, teóricos e metodológicos da "teoria da práxis", mostrando a indissociabilidade entre teoria crítica e ação transformadora. Por fim, nas considerações finais reafirmamos a posição inicial em recolocar o marxismo como instrumental fundamental na compreensão das políticas educacionais, já que estão imersas na sociedade capitalista contemporânea, hoje hegemônica.

\section{Na sociedade de classes a quem serve o conhecimento?}

A ciência está sendo desafiada a compreender controvérsias, paradoxos e contradições aparentemente insolúveis. A ousadia intelectual de Einstein, por exemplo, ao promover uma ruptura epistemológica, propugnando que a natureza da luz era onda-partícula (fóton) "[...] foi não apenas olhar para o sistema de idéias 
estabelecido, mas promover a ruptura com aquele para desvendar o paradoxo". (LEHER, 2010, p. 11)

Esse autor também afirma que nas Ciências Sociais, em outra dimensão, muitas contradições e paradoxos têm gerado intensas controvérsias teórico-políticas, exigindo ousadias epistemológicas. O autor explica:

Os determinantes objetivos e subjetivos das chamadas Revoluções de Veludo, no Leste Europeu, da Queda do muro de Berlim, do desmonte da União Soviética, no rastro da crise estrutural do capitalismo dos anos 1970 e que levaram ao neoliberalismo, promovendo deslocamentos no sistema de Estados, ainda precisam ser mais bem conhecidos para que o socialismo possa ganhar força na disputa pela hegemonia. (LEHER, 2010, p. 11)

Também é preciso compreender como a social-democracia européia assimilou o neoliberalismo e, mais do que isso, passou a ser operadora das políticas neoliberais, a exemplo dos governos Mitterrand e González, redefinindo a agenda da social-democracia mundial. (LEHER, 2010, p. 11) Esses acontecimentos que transformaram o mundo nos anos 1980 e 1990 atingiram mais tarde a América Latina, promovendo mudanças e reconfigurando a direita e esquerda em vários países.

O deslocamento dos conceitos de exploração/expropriação para exclusão/inclusão, por exemplo, é fundamental para que possamos compreender como os dominantes dominam, pois a partir desse deslocamento, um aparato de noções e idéias é difundido para que os chamados excluídos vislumbrem alguma possibilidade de inclusão social.

O Coletivo de Estudos de Política Educacional ${ }^{4}$ (CNPq/Fiocruz-EPSJV) tem realizado investigações, em especial a partir da década de 1990, produzindo conhecimento teórico rigoroso no sentido de contribuir na abertura de novas perspectivas para as lutas e estratégias anticapitalistas. O livro A nova pedagogia da hegemonia: estratégias do capital para educar o consenso (2005) alcançou grande impacto na academia e entre os movimentos sociais, tornando-se uma obra de referência.

A partir de então, o Coletivo tem-se dedicado a mapear autores, conceitos e noções presentes nas formulações da Terceira Via. ${ }^{5}$ A perspectiva de análise desses teóricos sugere que:
(4) Cf. O último livro do Coletivo denominado Direita para o social e esquerda para o capital: intelectuais da nova pedagogia no Brasil foi organizado por Lúcia Ma Wanderley Neves, (2010). 
(5) A Terceira Via se constitui em uma alternativa de análise sobre as mudanças que ocorreram em âmbito mundial no capitalismo.

Parcela significativa dos teóricos que defendem essa análise sugere que as relações sociais capitalistas estariam definitivamente superadas ou teriam perdido a relevância na constituição e na dinâmica das sociedades contemporâneas. Anthony Giddens sociólogo britânico renomado por sua Teoria da Estruturação é figura de proa do novo trabalhismo britânico e teórico pioneiro da Terceira Via, tem mais de vinte livros publicados ao longo de duas décadas. Trabalhou como assessor do ex-Primeiro-Ministro britânico Tony Blair.

(6) O conceito marxista de ideologia é compreendido em seu sentido negativo, crítico, ou seja, a ideologia manifesta-se quando os sentidos assumidos pelas formas simbólicas, que se expressam nas falas cotidianas, nas representações e nos discursos complexos servem para manter relações de poder que sustentam e perpetuam os mecanismos de exploração e dominação. (THOMPSON, 1995 apud BARBOSA, 2010)
[...] esse 'novo mundo' exigiria novos nexos entre razão e realidade para não deixar escapar o que estaria diante de nossos olhos: as experiências multifacetárias, a diversidade social e política, as novas interações entre local e global, as novas identidades culturais e o aparecimento de indivíduos mais autônomos e reflexivos. O ponto comum assumido pelos intelectuais e suas teorias é que as referências do passado teriam perdido a validade. Portanto, algumas linhas teóricas de interpretação da realidade e as formas tradicionais de organização e intervenção política ter-se-iam tornado obsoletas. (MARTINS; NEVES, 2010, p. 23)

Assim, analisando as obras de autores distintos - Alain Touraine, Adam Shaff, Robert Putman, Peter Drucher, Boaventura de Souza Santos, Manuel Castells, Edgar Morin, Zigmunt Bauman, Michel Hardt e Antônio Negri -, alguns de direita, outros de esquerda não marxista, outros ainda ex-marxistas, o Coletivo extrai o pensamento fundamental desses autores, que convergem para os seguintes pontos: impossibilidade da revolução, fim da luta de classes, e a defesa da tese de que as energias utópicas devem ser direcionadas para a sociedade civil, compreendida, majoritariamente, como parte de um esquema de três vértices: Estado, sociedade e mercado (LEHER, 2010, p. 16).

Apesar da defesa da Terceira Via, ou desse "novo mundo" descrito e analisado pelos intelectuais da hegemonia, os sinais de barbárie se multiplicam, seja na esfera material, com o processo de exclusão social galopante no Brasil e no mundo, sejam na esfera cultural e espiritual, com a crescente perda de sentido da existência humana indicando que o processo de acumulação de capital no mundo contemporâneo precisa cada vez menos de pessoas.

Simões Barbosa (2010, p. 10), ao discutir o enfrentamento do capitalismo na área da saúde, através do referencial marxista, afirma que:

Nos tempos que correm, em que o campo simbólico encontra-se profundamente dominado por conceitos e valores ideológicos, ${ }^{6}$ que justificam e sustentam o capitalismo em todas as sua dimensões, advogamos que a 'teoria da práxis', uma das denominações do marxismo, é mais necessária do que nunca, tanto para desmascarar a (ainda) renitente tese da neutralidade do conhecimento, como para nos conclamar, mais uma vez, ao enfrentamento do capitalismo, em particular no campo científico-acadêmico. 
A mesma autora complementa sua argumentação, afirmando que:

Vivemos tempos nebulosos, em que as palavras perdem seus sentidos históricos e políticos, os significados tornamse múltiplos, ambíguos, vagos, retóricos e, mesmo quando se assume um tom de crítica, muitas vezes esta é superficial e genérica, contra uma sociedade abstrata, contra poderes abstratos, contra processos que, embora reconhecidamente tornem a sobrevivência ameaçada, não tem denominação e, portanto, entendimento. (BARBOSA, 2010, p. 10)

Nessa mesma linha de raciocínio Frigotto e Ciavatta (2003) afirmam que as palavras que usamos para nomear as coisas, fatos e acontecimentos não são inocentes, inclusive os conceitos resultantes de um processo de elaboração sistemática e crítica ou científica, pois estão vinculados aos interesses de determinados grupos, classes ou frações de classes. Portanto, toda a linguagem, mesmo a denominada científica, é ideológica.

Simões Barbosa (2010) apropriando-se de Bourdieu (2000) explica que o sociólogo francês ao analisar esta questão classificou como "imperialismo simbólico" a supressão do léxico sociológico contemporâneo de conceitos como: capitalismo, classe, exploração, dominação, desigualdade, dentre outros, revogados sob o pretexto de obsolescência ou impertinência. A gravidade desta questão, diz Bourdieu (2000, p. 10-11), "é que essa 'nova vulgata' ideológica instituiu como conceitos 'universais' seus próprios termos - diversidade, identidade, diferenças, fragmentação etc. - na constituição do campo teórico genericamente denominado 'multiculturalismo'".

Também Barbosa (2010) ao criticar o sentido abstrato das teorias sociais atualmente hegemônicas, distanciadas do mundo concreto, apropria-se de Mary Castro (2000), indicando que esse discurso rompe com a "unidade-de-teoria-e-prática-marxista", como decorrência política, que passa a dar ênfase a uma agenda em defesa das diferenças, pela afirmação de identidades diversas, por igualdade de oportunidades e de direitos 'parcializados' - para mulheres, negros, indígenas, homossexuais e agora os 'novos pobres' - refletindo um posicionamento que não pretende investir nas condições materiais que tornaria possível o exercício dos direitos, fragmentando a abordagem e o enfrentamento do capitalismo enquanto totalidade social, reduzindo a compreensão das relações sociais a práticas discursivas. 
Em relação a reformas educacionais que ocorreram no Brasil nos anos 1990, por exemplo, desapareceram vocábulos como "educação integral", "omnilateral", "laica", "unitária", "politécnica" ou "tecnológica" e "emancipadora", realçando-se o ideário da "polivalência", da "qualidade total", das "competências", do "cidadão produtivo" e da "empregabilidade". (FRIGOTTO; CIAVATTA, 2003, p. 46)

Portanto, a difusão dessa nova linguagem, onde estão ausentes capitalismo, classe, exploração, dominação, desigualdade e tantos outros vocábulos, sob o pretexto de absolescência ou de presumida impertinência é produto de um imperialismo simbólico, que não é inocente.

No campo da educação, Frigotto (2004) ao analisar a relação entre trabalho, conhecimento, consciência e a educação do trabalhador diz que a compreensão concreta da prática educacional na sociedade de classes, como uma prática contraditória, está longe de ser assimilada ao nível da teoria e das transformações históricas. Esse seu posicionamento tem como fundamento a homogeneização superficial do discurso crítico, cuja prática reflete a interiorização das concepções e categorias do humanismo, do positivismo e do funcionalismo, que significa a assunção da concepção burguesa de trabalho, de educação e de formação do trabalhador. Assim, põe-se como limite da análise e da ação as perspectivas, valores e concepções da sociedade das mercadorias.

Segundo o mesmo autor, a concepção burguesa de trabalho constrói-se historicamente, mediante um processo que o reduz a uma coisa, a um objeto, a uma mercadoria que aparece como trabalho abstrato em geral, força de trabalho. Iguala-se trabalho a ocupação, emprego, tarefa, perdendo-se a compreensão de que o trabalho é uma relação social fundamental que define o modo humano de existência.

Essa concepção de trabalho é exposta hoje de forma mais ardilosa e sutil, aparecendo como direito dentro de uma igualdade abstrata. O trabalho aparece como uma virtude universal, pela qual a acumulação de capital é legítima, e não como única fonte de produção do valor, permitindo, portanto, nas relações de produção capitalistas, a expropriação, a mais-valia. No bojo das teorias neocapitalistas, que incluem as perspectivas de co-gestão e participação nos lucros, reforça-se a ideia de que a superação das desigualdades entre as classes é possível sem a ruptura da lógica do valor. (FRIGOTTO, 2004) 
O mesmo autor também indica que o modo dominante de apreender e de orientar na prática a relação trabalho e educação passa pelas seguintes dimensões:

a)Uma dimensão moralizante, tão ao gosto da moral burguesa, onde o trabalho manual e intelectual aparecem como igualmente dignos, formadores do caráter e da cidadania; b) uma dimensão pedagógica, onde o trabalho aparece como um espécie de laboratório de experimentação - aprender fazendo; c) , finalmente, uma dimensão social e econômica, onde os filhos dos trabalhadores podem autofinanciar sua educação (escolas de produção). Essas perspectivas, enquanto não se subverter radicalmente a relação social que as orienta, situam-se no limite imposto por ela. (FRIGOTTO, 2004, p. 16)

Concluindo esse primeiro momento, pensamos que o problema central situa-se na superação da propriedade privada dos meios de produção, eliminando o caráter de mercadoria que assume a força de trabalho e o conjunto de relações sociais no interior do capitalismo. Assim, a problemática que envolve as propostas educativas sobre trabalho e educação, como é o caso da educação profissional, indicam uma debilidade e insuficiência de direção teórica e de investigação crítica, o que não nos permitiria apreender as contradições, conflitos, especificidades, diferenças, em suma, a diversidade histórica. Portanto, não se trata apenas de um divórcio entre teoria e prática. Frigotto (2004, p. 24) explica:

Ao enfatizar o mundo do trabalho, na sua historicidade, como relação social fundamental que não se reduz à ocupação, tarefa, emprego, mas que não os exclui, e que abarca o conjunto de relações produtivas, culturais, lúdicas, etc., estou querendo sinalizar que ai se situa o lócus da unidade teórica e prática, técnica e política, ponto de partida e chegada das ações educativas que, na escola, nos sindicatos, na fábrica, interessam à luta hegemônica das classes populares.

Embora não esteja investida da obrigatoriedade e do princípio da universalização como a educação básica, o direito de acesso à educação profissional é sem sombra de dúvida uma necessidade social incontestável, contudo é preciso ir mais além, temos que tornar sua legalização uma questão ética.

Estamos convencidos de que, hoje, como nos indica Oliveira (1987) o desafio mais complexo para aqueles que se fundamentam 
(7) Tomamos como referência o Documento Base - Educação

Profissional Técnica de Nível Médio Integrada ao Ensino Médio. MEC/ Secretaria de Educação Profissional e Tecnológica, Brasília, dezembro de 2007. no materialismo histórico é saturar de historicidade os conceitos e as categorias analíticas para que possamos compreender, de fato, a sociedade contemporânea e, particularmente, a educação.

Explicitada nossa compreensão sobre a sociedade capitalista contemporânea e os limites impostos a educação da grande maioria da classe-que-vive-do-trabalho, passaremos a apresentar e discutir a historicidade da educação profissional no Brasil.

\section{A Historicidade da Educação Profissional ${ }^{7}$}

A relação entre educação básica e profissional no Brasil é marcada, historicamente, pela dualidade. As origens da educação profissional, como responsabilidade do Estado, surgem a partir de 1809, com a criação do Colégio de Fábricas pelo Príncipe Regente, futuro D. João VI e é marcada pelo assistencialismo a crianças pobres, órfãos e abandonadas, com o objetivo de ampará-las. (BRASIL, 1999 apud BRASIL, 2007)

No início do século XX o enfoque da Educação Profissional passa a ter como objetivo a preparação de operários - pobres e humildes - para o exercício profissional. Assim, em 1909 o presidente Nilo Peçanha cria as Escolas de Aprendizes Artífices, instalando no ano seguinte dezenove dessas escolas em várias unidades da Federação.

As décadas de 1930 e 1940 do século passado são marcadas pelas transformações políticas, econômicas e educacionais, quando se fortalece a nova burguesia industrial, que substitui as oligarquias cafeeiras, exigindo do governo posições mais efetivas em relação à educação nacional.

Assim, a partir dos diversos Decretos-Lei, conhecidos como Leis Orgânicas da Educação Nacional - denominada de Reforma Capanema - ficou evidenciada a legalidade da educação no país e em especial a Educação Profissional, pois foram definidas leis específicas para a formação em cada ramo da economia.

A educação brasileira, denominada de regular, passa a estruturar-se em dois níveis: a educação básica (primário e secundário, este último dividido em ginasial e colegial) e a superior. A educação profissional, desvinculada da educação básica, era constituída pelos cursos normal, industrial técnico, comercial técnico e agrotécnico e não habilitavam para o ingresso ao ensino superior.

Percorrendo o caminho da historicidade da educação profissional, outro momento marcante na vida do país e particularmente no 
campo da educação foi o período que antecedeu a LDB n 4.024/61, quando a política educacional refletia os conflitos entre modelos distintos de desenvolvimento. A polarização de interesses entre os setores populares e populistas acabaram pleiteando extensão da rede escolar gratuita e equivalência entre ensino médio propedêutico e profissionalizante. Em contraposição, os representantes da classe hegemônica reivindicavam a redução da ação da sociedade política sobre a escola, defendendo a privatização do ensino e a subvenção do Estado para essas escolas, sem direito a fiscalização, pois o que devia prevalecer era a liberdade de ensino. Aparentemente a LDB/61 acabava com a dualidade, contudo, na prática era mantida pelos currículos.

No governo militar, década de 1970, houve mais uma reforma da educação básica promovida pela Lei no 5.692/71 - que reestrutura o Ensino de $1^{\circ}$ e $2^{\circ}$ graus. O aspecto polêmico foi, exatamente, a profissionalização obrigatória em nível do $2^{\circ}$ grau. Essa Lei veio atender a demanda da nova fase de industrialização do país que carecia de mão-de-obra qualificada. Vivia-se a fase do "milagre brasileiro" e a opção política do governo militar foi dar uma resposta diferente às demandas educacionais das classes populares, criando 'possibilidades' à inserção dos trabalhadores no mercado de trabalho, em função do desenvolvimento do capitalismo brasileiro naquele momento histórico.

Ao final dos anos 1980 e primeira metade dos anos 1990, após a promulgação da Constituição Federal de 1988, ocorre no Congresso Nacional o processo que culmina com a atual LDB no 9.394/96, quando a profissionalização obrigatória de $2^{\circ}$ grau deixa de existir, exceto nas Escolas Técnicas Federais e nas Escolas Agrotécnicas.

Portanto, o debate sobre formação técnico-profissional, no Brasil, tem sido intenso e controverso, desde a década de 30 do século passado. A criação dos Sistemas Nacionais de Formação Profissional e do Sistema de Escolas Técnicas Federais, nos anos 40 daquele século, é de certa forma, resultado desse debate.

Da análise que empreendemos até agora sobre a historicidade da educação profissional no Brasil, podemos afirmar que, aproximadamente 40 anos depois de iniciada a experiência de educação e formação profissional, no período constituinte e posteriormente, na fase de elaboração da atual Lei de Diretrizes e Bases da Educação (LDB/96), o tema da formação técnico-profissional foi debatido intensamente. A aprovação da LDB, em 1996, foi resultado de 
um projeto que se desenvolveu paralelamente a um processo de negociação balizado por mais de 30 instituições da sociedade civil. Esse projeto expressa, na sua essência, a subordinação do ensino fundamental, médio e superior e da formação técnico-profissional ao ajuste mais amplo da sociedade brasileira à nova (des)ordem mundial. (FRIGOTTO, 1999). O mesmo autor explica:

Por se tratar de uma prática social constituída e constituinte de relações sociais, a formação técnico-profissional está, na sua organização, financiamento e concepção político-pedagógica, imbricada na crise societária deste final de século. Esta crise é, ao mesmo tempo, sócio-econômica, teórica e ético-política. No âmbito sócio-econômico a crise se explica pela desordem dos mercados mundiais, hegemonia do capital especulativo, monopólio da ciência e da técnica, desemprego estrutural e maximização da exclusão. No plano teórico, a crise se revela na incapacidade de referências de análise darem conta dos desafios do presente. Por fim, a crise ético-política, que se manifesta pela naturalização da exclusão, da violência e da miséria. (FRIGOTTO,1999, p. 1)

Frigotto (1999, p. 1, grifos do autor) ainda complementa:

Nessas circunstâncias, tanto no plano societário mais amplo quanto em políticas específicas como é o caso da formação técnico-profissional, o risco é o surgimento de atitudes e medidas oportunistas, simplificadoras, ou de soluções mórbidas. A todo instante ouvimos falar que estamos em tempo de reestruturação produtiva de economia competitiva e de globalização. E, em face dessa realidade posta como irreversível, a escola e as instituições de formação técnico-profissional necessitam ajustar-se. Esse ajuste postula uma educação e formação profissional que gere um 'novo trabalhador' - flexível, polivalente e moldado para a competitividade. Cabe à escola e aos centros de formação profissional, nessa perspectiva, desenvolver um banco variado de competências e de habilidades gerais, específicas e de gestão. Diante das mudanças no mundo do trabalho, mormente da crise estrutural do emprego, já não se pensa em formar para o posto de trabalho, mas formar para a 'empregabilidade'.

Assim, as reformas que ocorreram no campo educativo e, especificamente na formação técnico-profissional, fazem parte da estratégia do ajuste estrutural que levou o Estado a promovê-las nos 
planos: político-institucional e econômico-administrativo. Dessa forma, explica Frigotto (1999, p. 9):

O caráter minimalista e desregulamentador da nova Lei de Diretrizes e Bases da Educação Nacional (9.394 de 20.12.96) se coaduna tanto à estratégia de impor pelo alto um projeto preconcebido, quanto com a tese do Estado 'mínimo' com a tríade do ajuste estrutural: desregulamentação, descentralização e privatização.

A nova conformação que assumiu o ensino técnico-profissional no final do século XX é resultado desse caráter minimalista da LDB/96. A primeira regulamentação veio através do Projeto de Lei $n^{\circ} 1.603 / 96$, que com a aprovação da LDB, automaticamente se transforma em Decreto $n^{0} 2.208 / 97$, impondo a reforma, que, segundo Frigotto (1999, p. 10)

[...] representa uma regressão ao dualismo e exacerbação da fragmentação. O dualismo se cristaliza pela separação das dimensões técnicas e políticas, específicas e gerais, particulares e universais e pela separação do nível médio regular de ensino da rede não regular de ensino técnico-profissional com organização curricular específica e modular.

A partir dessas reformas podemos concluir que a educação regular e, particularmente, a formação técnico-profissional passam a ser, como bem denomina Frigotto (1999) "a galinha dos ovos de ouro" que pode levar o Brasil a ajustar-se a nova (des)ordem mundial - de exclusão quando preconiza uma educação desintegradora, isto é, só para aqueles que consigam desenvolver "competências" reconhecidas pelo mercado. Nesse ideário a educação deixa de ser um direito subjetivo de todos.

Atualmente sob uma nova perspectiva, discute-se em âmbito nacional, o Ensino Médio Integrado, particularmente, após revogação do Decreto $n^{\circ} 2.208 / 97$, que propõe a integração entre a educação profissional técnica de nível médio e o ensino médio, inclusive na modalidade de Educação de Jovens e Adultos (EJA). ${ }^{8}$ Trata-se de uma concepção de educação que, desafiada pelas contradições da realidade concreta, pressupõe a integração de dimensões fundamentais da vida - trabalho, ciência e cultura - num processo formativo que possibilite aos trabalhadores o acesso aos conhecimentos (científicos, éticos e estéticos) produzidos histórica e cole- 
tivamente pela humanidade, assim como aos meios necessários à produção de sua existência e à sua emancipação como classe social.

Como nos mostra Saviani (2007) é uma concepção radicalmente diferente daquela que propõe o ensino médio profissionalizante, entendido como adestramento em uma determinada habilidade, sem desenvolver na formação dos educandos o conhecimento dos fundamentos daquela habilidade. Pior, não articula o desenvolvimento daquela habilidade com o conjunto do processo produtivo.

Não podemos desconsiderar que a concepção de ensino médio integrado, como exposto anteriormente, se constitui no grande desafio da próxima presidente do Brasil, que assumirá em 2011, pois a visão de articulação e não de integração da formação profissional à educação básica está sendo defendida pelos dirigentes do Sistema "S", delegados das Conferências Estaduais e mais recentemente pelos delegados na Conferência Nacional, representando a perspectiva do dualismo e adestramento. Nesse sentido, afirma Frigotto (2010), dois obstáculos devem ser enfrentados pela sociedade e governo:

Primeiramente o de modificar as diretrizes promulgadas pelo Conselho Nacional de Educação que induzem a compreensão do ensino médio a simples arranjos do Decreto n².208/97, na perspectiva de articular e não de integrar, e, em última instância, ao retorno do profissionalizante da reforma $n^{\circ}$ 5.692/71, um adestramento rápido com vistas ao mercado de trabalho. O segundo é o de quebrar a barreira de resistências das políticas estaduais sob quem está a prerrogativa da oferta do ensino médio. (FRIGOTTO, 2010, p. 38)

Para superarmos o dualismo até hoje existente nas escolas públicas brasileiras de ensino médio, além dos dois obstáculos citados acima, seria fundamental seguir o exemplo de educação profissional integrada ao ensino médio desenvolvida na Escola Politécnica de Saúde Joaquim Venâncio, vinculada à Fundação Oswaldo Cruz, que atende aos jovens das camadas populares e de classe média.

Recentemente, na publicação dos resultados do Exame Nacional do Ensino Médio (ENEM) a Escola Politécnica de Saúde Joaquim Venâncio obteve o melhor desempenho. Por que todas as escolas públicas de ensino médio não têm esse mesmo desempenho? Quem responde a essa questão, segundo Frigotto (2010, p. 38-39), de forma correta política e cientificamente é seu diretor professor André Malhão: 
Primeiramente, $[\ldots]$ adverte que qualquer comparação com as demais escolas da rede pública é inadequada, porque as mesmas estão longe de trem as condições minimamente comparativas em termos de professores qualificados (a maioria com mestrado doutorado), com grupos de pesquisa, laboratórios atualizados, biblioteca, espaço físico. Em segundo lugar, o diferencial está na proposta política e pedagógica da escola, centrada no debate e concepção da escola unitária e politécnica. Uma escola comprometida em formar jovens que articulem ciência, cultura e trabalho e lhes dê possibilidade de serem cidadão autônomos. Que possam escolher seguir seus estudos ou ingressar na vida profissional.

Enquanto a escola Joaquim Venâncio já existe há 25 anos, desenvolvendo o ensino médio integrado a educação profissional, hoje, discute-se nacionalmente nos Institutos Federais, na academia, órgãos do governo federal e estadual e pela sociedade civil organizada um documento, ${ }^{9}$ que tem como objetivo ampliar o debate sobre a atualização das diretrizes nacionais da educação profissional técnica de nível médio, que se originou a partir da realização de duas audiências públicas promovidas pelo Conselho Nacional de Educação (CNE). Em síntese esse documento defende um projeto de ensino médio que integre trabalho, ciência e cultura, na perspectiva de uma formação unitária, politécnica e omnilateral.

Esperamos que o resultado dessa discussão ampla com os sujeitos responsáveis pela educação profissional nas instituições federais e estaduais, além dos intelectuais comprometidos com essa discussão, seja promissor, assumindo a educação profissional como princípio educacional, superando o pragmatismo que reduz a educação a sua funcionalidade. Garantir a formação básica unitária e a possibilidade de formação profissional para a maioria da classe-que-vive-do-trabalho se constitui em compromisso ético-político da sociedade brasileira.

\section{Considerações Finais}

Esse ensaio tem a expectativa de ter contribuído na discussão da educação profissional, tomando como referência os fundamentos do marxismo, conferindo-lhe atualidade. Fomos radicais, isto é, tentamos demonstrar que não dá para discutir a educação profissional sem ir as suas raízes, desvelando, fundamentalmente,
(9) Cf. Documento produzido pelo Grupo de Trabalho (instituições públicas de ensino, representações de trabalhadores e de associações de pesquisa científica) para a formulação de contribuições ao debate sobre Diretrizes Curriculares Nacionais para a Educação

Profissional Técnica de Nível Médio, 2010 
a lei do valor, que rege a sociedade capitalista na qual a educação está imersa.

Nunca as sociedades humanas conheceram como no capitalismo contemporâneo, mundializado e financeirizado, uma circulação tão generalizada de formas simbólicas, exercendo tanta influência sobre as formas de representar o mundo. Como advoga Thompson (1995 apud BARBOSA, 2010, p. 15)

[...] a natureza e a abrangência da circulação de formas simbólicas assumiu [atualmente] um aspecto novo e qualitativamente diferente, na medida em que os meios técnicos e as instituições orientadas para a acumulação capitalista possibilitaram a produção, reprodução e circulação das formas simbólicas numa escala antes impensável. O poderoso império do que hoje se denomina 'meios de comunicação de massa'.

O mundo está ideologizado, exigindo de todos nós um conhecimento crítico capaz de desvendar as "cortinas de fumaça" que encobrem os complexos problemas que enfrentamos na esfera educacional, mas não só nela. Simões Barbosa (2010), apropriando-se de Romito (1997) afirma que atribuir um conceito torna o fenômeno visível, perceptível, (re)colocando-o no plano da concretude, viabilizando a crítica e seu enfrentamento. Assim, "nomear envolve tornar visível o que era invisível, definir como inaceitável o que era aceitável e insistir que o que era naturalizado é problemático". (ROMITO, 1997, p. 16)

$\mathrm{Na}$ "teoria da práxis" os fenômenos naturais e sociais não são abstrações do pensamento, são reais, específicos, ocorrem em lugar e tempo determinados, sob condições particulares de existência e em constante processo de transformação. Assim, os movimentos sociais, institucionalizados ou não, plantaram há algum tempo (alguns da década de 1950), por meio da luta em defesa da escola pública, gratuita e de qualidade, as sementes da educação tecnológica a respeito da educação do futuro.

Leher (2002, p. 172) explica:

[Foram] grupos de mulheres do Movimento de Educação da Zona Leste de São Paulo, Associação de Pais e Mestres, Sindicatos dos Trabalhadores em Educação, Núcleos de Educação dos partidos de esquerda, que sabem, sentem, vivem, na carne, as contradições advindas da assimetria entre a riqueza socialmente produzida, por meio do trabalho, e as condições materiais e 
espirituais de vida. O drama da pobreza não é apenas decorrente dos baixos salários, mas da educação focalizada, minimalista, somente capaz de produzir aberturas para o futuro pelo compromisso ético-político de sujeitos nas salas de aula, nos movimentos religiosos, no âmbito familiar etc.

Contudo, esses sujeitos, hoje, estão sendo submetidos ao silêncio e ao esquecimento. A classe hegemônica anuncia como seus parceiros os "novos" movimentos sociais, caracterizados como "terceiro setor" ou ONG, vistos como vivacidade da sociedade civil, liberta de um passado de confrontação de corte classista. As ideologias dominantes pregam que os conflitos podem ser solucionados com base no melhor argumento. O entendimento é o vetor discursivo. (LEHER, 2002). O mesmo autor complementa:

Indubitavelmente, a pauta econômica hoje se reveste de um caráter político de fundo, pois atinge o âmago das políticas neoliberais, prisioneiras (e artífices) da voluptuosidade do capital financeiro. A reivindicação da responsabilidade do Estado com a manutenção e o desenvolvimento do ensino público é, neste contexto, uma insígnia radical e fecunda. Os desdobramentos dilacerantes do desenvolvimento desigual do capitalismo não podem ser esquecidos. A pauperização dos decentes e o processo de objetvação/fetichização que o capital impõe ao trabalho pedagógico estão inscritas em uma reestruturação que prevê a perenização da condição cultural dependente, expressão simbólica da condição capitalista dependente investigada por Florestan Fernandes. (LEHER, 2002, p. 173)

Concluindo, o referencial marxista não dissocia os processos simbólicos dos materiais, pois não se pode desconsiderar o quanto o campo educacional tornou-se refém dos interesses mercantis do capital, que utiliza a ideologia neoliberal como suporte para defender o mercado como esfera reguladora da vida social, disseminando valores individualistas, consumistas e competitivos, minando as bases da solidariedade social.

Por outro lado, as teorizações dos autores que vislumbram um 'novo mundo', como explicita Neves (2010), apesar de serem produções individuais e de caráter exclusivamente acadêmico, no plano real, pela mediação da política e em função do estágio de desenvolvimento das relações de poder, essas teorias se transformam em referências de criação de uma identidade ideológica, que acaba 
produzindo uma organicidade de pensamento e de ação, servindo de cimento para a coesão social e a relação entre dirigentes e dirigidos nos marcos do capitalismo.

\title{
The Professional Education in the Context of Capitalist Society Brasileira: analysis from the critical-dialectical method
}

\begin{abstract}
The intent of this essay is replacing the Marxism as the theoretical, methodological, epistemological option and policy in the field of education, particularly of professional education. We seek, schematically, presenting three dimensions articulated, that called professional education predicaments facing the peripheral capitalism in Brazil. Initially discussed the symbolic field as expression of ideologies that underpin the capitalism and that uses, among other strategies, the silencing of the Marxism, and even about capitalism in order to deflate the criticism and questioning. Then relate these professional education mechanisms, identifying how the neoliberal capitalism operates. Also we present some methodological, theoretical and philosophical underpinnings of "theory of praxis", showing the inseparability between critical theory and transformative action. Finally, in concluding remarks reaffirm the initial position in replacing the Marxism as fundamental tool for understanding of educational policies, as they are immersed in the contemporary capitalist society, hegemonic today.

Keywords: Professional education. Neoliberal capitalism. Work. Theory of Praxis. Educational policies.
\end{abstract}

\section{Referências}

ANTUNES, Ricardo. Os sentidos do trabalho: ensaio sobre a afirmação e a negação do trabalho. São Paulo: Boitempo Editorial, 1999.

BARBOSA, Regina Helena Simões. A 'Teoria da Práxis': retomando o referencial marxista para o enfrentamento do capitalismo no campo da saúde. Trabalho, Educação e Saúde, Rio de Janeiro, v. 8, n. 1, p. 9-26, 2010.

FRIGOTTO, G. A relação da educação profissional e tecnológica com a universalização da educação básica. In: MOLL, Jaqueline et al. Educação profissional e tecnológica no Brasil contemporâneo: desafios, tensões e possibilidades. Porto Alegre: Artmed, 2010. p. 25-41.

Globalização e crise do emprego: mistificações e perspectivas da formação técnico-profissional. Boletim Técnico do SENAC $n^{\circ} 25$ maio/ago. 1999.

A polissemia da categoria trabalho e a batalha das idéias.

Revista Brasileira de Educação. v.14 n. 40 jan./abr. p. 168-194, 2009.

Trabalho, conhecimento, consciência e a educação do

trabalhador: impasses teóricos e práticos. In: GOMES, Carlos Minayo et 
a1. Trabalho e conhecimento: dilemas na educação do trabalhador. 5. ed. São Paulo: Cortez, 2004. p. 13-26.

.; CIAVATTA, M. Educar o trabalhador cidadão produtivo ou o ser humano emancipado? Revista Trabalho, Educação e Saúde. v. 1, n. 1, Rio de Janeiro, p. 45-60, 2003.

LEHER, Roberto. Tempo, autonomia, sociedade civil e esfera pública: uma introdução ao debate a propósito dos "novos" movimentos sociais na educação. In: GENTILI, Pablo; FRIGOTTO, Gaudêncio. A Cidadania Negada: políticas de exclusão na educação e no trabalho. 3. ed. São Paulo: Cortez Editora; CLACSO, 2002. p. 145-176.

MARTINS, André S.; NEVES, Lúcia Maria Wanderley. A nova pedagogia da hegemonia e a formação/atuação de seus intelectuais orgânicos. In: NEVES, Lúcia Maria Wanderley. (Org.). Direita para o social e a esquerda para o capital: intelectuais da nova hegemonia no Brasil. São Paulo: Xamã, 2010, p. 23-38.

MARX, Karl; ENGELS, Frederich. Textos sobre educação e ensino. Tradução de Rubens Eduardo Frias. São Paulo: Centauro, 2004.

NETTO, José Paulo; BRAZ, Marcelo. Economia Política: uma introdução crítica. 4. ed. São Paulo: Cortez, 2008. (Biblioteca básica de serviço social; v.1).

NEVES, Lúcia Maria Wanderley (Org.). Direita para o social e a esquerda para o capital: intelectuais da nova hegemonia no Brasil. São Paulo: Xamã, 2010.

OLIVEIRA, Francisco. O elo perdido: classe e identidade de classe. São Paulo: Brasiliense, 1987.

SAVIANI, D. Trabalho e educação: fundamentos ontológicos e históricos. Revista Brasileira de Educação. Campinas, SP, v. 12, n. 34, p. 152-165, jan./abr. 2007.

Recebido: 06/11/2012 | Aprovado: 28/11/2012 